\title{
Expanding Industrial Architecture Through Creativity in Manufacturing
}

\author{
Eric Mwanga Balama*, Qin Yuanjian, Göttlieb Moshi, Jacob Julius Rombo \\ School of Management, Wuhan University of Technology, Wuhan, P.R. China, 430070
}

\begin{abstract}
Throughout the decades, industrial firms have sought clearly in calling on industry production experts to production more producible prototypes for manufacturing purposes. This can typically be accomplished by evaluating the current product production manufacturing system capabilities, and difficulties often arise due to challenges to combining product description and manufacturing operations. This paper will discuss how advances in manufacturing (as new fabrication capabilities) will add to the industrial design space for product design engineers, enabling more design flexibility and increasing efficiency by eliminating and/or loosening constraints on product designs. The findings from a series of industrial case studies provide encouraging effects on how technological technologies will positively impact the growth of industrial design engineers' solution space. The findings from a series of industrial case studies provide encouraging effects on how technological technologies will positively impact the growth of industrial design engineers' solution space. To order to foster product creativity, design managers are expected to test new technologies, new design techniques and new manufacturing (working) practices.
\end{abstract}

Keywords: Industrial Design; Design for X; Design to X, Product Innovation, Manufacturing Systems, Production Innovation.

DOI: $10.7176 / \mathrm{JRDM} / 71-05$

Publication date: November $30^{\text {th }} 2020$

\section{Introduction}

Throughout the decades, manufacturing firms have tried to develop manufacturability mainly through encouraging industrial design engineers to build more producible prototypes while taking into account the production system capability that is usable, using convergence of functions in the process more or less. In certain cases, obstacles and disparities hinder full convergence of product and manufacturing development M. Vielhaber and P. Stoffels, P.(2014), as industrial design engineers prefer to concentrate more on product output while manufacturing engineers are more focused on production quality. In this sense, the role of the growth of production is seen as the creation of innovative manufacturing methods required for the construction of a new product. The introduction of innovative methods and manufacturing techniques, called the developments in this article, which are typically applied for growing economic growth and efficiency on the shop floor, are another aspect of production development. Limited consideration has been given to 'manufacturing innovations' D. Romero, L. Larsson, A. Öhrwall Rönnbäck and J. Stahre.(2017) for innovative product designs,J. Lessing, L. Stehn and A. Ekholm (2015) despite being recognized as an important input in the early product development phases of manufacturing skills. Lewandowski et al C. Levandowski, D. Raudberget and H. Johannesson (2014) suggest that emerging developments and production techniques can be precedents to be co-ordinated in a suitable way to form the environment of industrial design.

The purpose of this paper is to discuss how, as mentioned above, manufacturing advances will lead to an increase in the industrial design space for product design engineers, and also product innovation. Manufacturing technologies from a number of manufacturing organizations are evaluated using 'producibility factors' as a link between efficient device capabilities and product growth.

This approach seeks to grant manufacturing technicians the same rank as innovative designers, not in the area of product designs but in this case in efficient programs, which brings both the spirit of design and of technology for creativity at the level of goods and production processes to the strategic advantages of the manufacturing firm in industrial design.

The findings from these case studies provide encouraging effects on how manufacturing technologies may have a positive impact on the growth of the industrial design engineers' space for solutions. Such (new) incentives will allow manufacturing engineers to explore new products, new production processes, and new methods of production (working) to promote product innovation by production innovation(s).

\section{Expanding the solution space for product design.}

The eXcellence (DfX) design and the Design to Properties (DtX) approaches are two approaches that enhance the fabricability of the product design, the definition of the product, with the manufacturing system capabilities that are available. The concept of manufacturability is J.G. Bralla(1999) "the fairly simple manufacturing of a product or component, its simplicity, its straightforward nature, its degree of reducing labour, resources and overhead costs 
and its freedom from inherent problems in production and processing."

Design for Manufacturability (DFM) addresses the task from both directions, which concentrates on limiting the potential area of product definition to the manufacturing system ability, while Design to Manufacturability (DtM) investigates how more 'liberty' is created in the definition of a product.

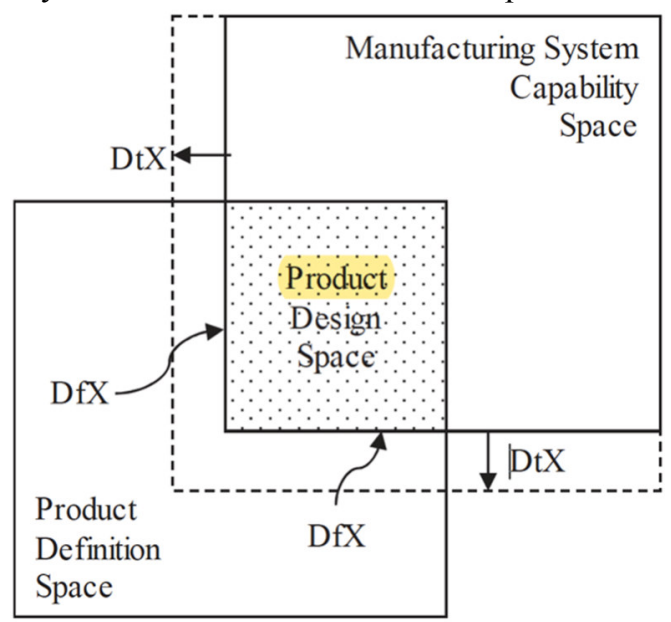

Fig. 1. Product Definition and Manufacturing System Capability Spaces Delimiting the Product Design Space (Adapted from J.G. Bralla(1999))

The actual 'definition of the product' and the 'space for the production system' is the overlaps, as shown in the Fig. 1 the product design space dependent on the product portfolio and the capacity of the production system based on production limitations and resource constraintF. Elgh and M. Cederfeldt (2008).

A. Design for Manufacturability eXcellence (DfX) for Industrial Design Engineers

Design for excellence (DfX) methodologies have historically introduced different techniques and related methods as a series of design criteria (e.g. Design for Manufacturing ( DfM) and Design for Assembly ( DfA) that help industrial design engineers produce and apply technical expertise to manage, improve or even create specific characteristics and features for a product design. Implementation of DfM and DfA has brought tremendous benefits including product simplification, reduction in production and assembly prices, and quality improvement T-C. Kuo, S.H. Huang and H-C. Zhang (2001).

Throughout the years, DfM\&A methodologies have concentrated on collecting various design rules and restrictions for industrial design engineers to limit their product concepts to the capacities of existing manufacturing technology, in many cases disregarding the possibilities provided by manufacturing developments to render viable product inventions (see current product definitions). A recent example of an advancement in production is the additive manufacturing technology which provides more geometry and functional freedom for industrial design engineers, as well as new synthesized materials with properties for their product designs I. Gibson, D.W. Rosen and B. Stucker (2015).

B. Design to Manufacturability Properties (DtX) for Manufacturing Engineers

More recently, methodologies for design to properties (DtX) have emerged as a set of parameters for manufacturing technologies (e.g. Design to Cost (DtC) and Design to Quality (DtQ)) to propose different approaches and corresponding methods to help manufacturing engineers design next-generation (production) systems.

These manufacturing systems may include new materials (such as foams, coatings, metals, polymers, powders, etc.), new manufacturing hardware (such as factory layouts, jigs, fixtures and other tools), new manufacturing processes (such as additive and subtractive processes) and new manufacturing (such as assembly processes). They are all capable of extending the domain of product designs for development to the present solution.

DtX methodologies involve asking manufacturing engineers to develop or extend manufacturing technology capacities to suit the creative product designs of industrial design engineers, ensuring that the imagination of a product specification does not outweigh the ingenuity to find a way to produce the product concept in a sustainable manner (cf. manufacturability). A recent example is the production of smart products for successful demolition to promote eco-product designs (e.g. Recycling Design (DfR) and Disassembly Design (DfD)).

\section{Methodology}

According to J. Landahl, C. Levandowski, H. Johannesson, R. Söderberg, K. Wärmefjord, J.S. Carlson, J. Kressin, O. Isaksson and J. Vallhagen (2016), there are many ways to production manufacturing, and these methods offer instructions for industrial production engineers on how to produce goods that are 'producible.'

Productivity is characterized by Best Manufacturing Practices Center of Excellence (1999) as "the relative 
ease with which the product can be produced as measured by yield, cycle times, and associated cost of options in (product) design, manufacturing processes, production and support, and tooling." In comparison, efficiency is "the production potential to manufacture a product in a reliable and effective manner to satisfy the design requirements for the product's functions and reliability"J. Vallhagen, J. Madrid, R. Söderberg and K. Wärmefjord (2016). This supports a close connection to the actions, functionality and efficiency of the product J. Vallhagen, J. Madrid, R. Söderberg and K. Wärmefjord (2016). It can therefore be seen as "a property of product production and manufacturing processes that encapsulates the ability to produce a product within cost and time limits, while maintaining a target level of quality and delivering a product that satisfies the relevant requirements"A.J. Ball (2015). 'Producibility' can also be seen as the result of a breath between design and manufacturing practices, as a lack of connection between product creation and production operations, where the failure of production (see production shortfalls) comes from the incompatibility of the concept of the product with the capability of its manufacturing system A.J. Ball (2015). Traditionally, comprehensive product identification and manufacturing method variations have been a focus area for understanding the risk of production losses A.J. Ball (2015).

According to J. Vallhagen, J. Madrid, R. Söderberg and K. Wärmefjord (2016), the word manufacturability is sometimes used in the meanings of productivity and context, though in many situations it is very similar, there is one dimension of productivity that can be defined as a difference between the two. In manufacturing, there is a strong link to the functions, characteristics and performance of the product, whereas in manufacturing, the function of the product and its characteristics are less of a concern, focusing instead on production optimisation. The explanation for this is that product sophistication and process development for production operation is not exactly the same.

a) Specification of criteria and metrics for the planned manufacturing processes-not for the average and

b) A holistic view where the production processes and product properties are treated as a whole-not analysed as separate parts, also known as the Integrated Product and Process Development Framework (IPPD). Awareness of the development mechanism is important when doing DfP. According to F. Elgh and M. Cederfeldt (2008), DfP must be carried out with 'listed targets' to be classified as 'producibility steps.' Seven considerations F. Eureka (1994) are suggested as suitable for assessing the effect of a particular product design on each phase of the product life cycle, including the production activity:

(1) production cost,

(2) quality,

(3) flexibility,

(4) risk,

(5) lead-time,

(6) efficiency, and

(7) environmental effects.

Such criteria are closely related to metrics frequently used to determine the efficiency of a production system M. Bellgran and E.K. Säfsten (2009):
(a) productivity,
(b) efficiency,
(c) cost
(d) quality, and
(e) time.

The most important goals of production growth are the refinement of these criteria.

Through this way, scholars propose that industrial design engineers use the DfX approach for describing the product (see basic characteristics and attributes) as a set of goals. The use of DtX methodologies is often suggested as a collection of efficiency measurements to define manufacturing engineers' potential for the production system (cf. performance). Therefore, in the field of product design, all Technology Groups (design and production) should be able to balance product design with engineering in a consistent and directed manner (e.g P.M. Milling and J. Stumpfe (2000) and J. Stumpfe (2001).

Table I attempts to explain the fundamental product design - manufacturing process experiences in the construction of a product.

\section{Research Design}

A case study approach K.M. Eisenhardt and M.E. Graebner (2008) was used to analyse in detail and collect rich data on creative production process improvement ventures and their impact on industrial processes and product design. Cases, i.e. product research ventures, were chosen by purposeful sampling M.B. Miles and A.M. Huberman (1984), choosing prominent developments in manufacturing processes where the intricacies of manufacturing technologies and their possible results may be revealed.

Data collection was conducted primarily through interviews with respondents (interviewees) who were involved in manufacturing innovation development projects in some way; either at certain stages or throughout 
the project (see Table 1). The interviews were semi-structured to provide rich material to provide the interviewees with a sense of how 'process advances' led to 'product developments' to what were the results and principles provided to both sides, industrial design engineers and manufacturing engineers by these process innovations.

Questions were asked about the cause or triggering element for manufacturing developments, e.g. what were the results (i.e. inventions) of manufacturing technology programs and who influenced the results (i.e., industrial design engineers and/or manufacturing engineers).

Table 1. Respondent Information

\begin{tabular}{|c|c|c|}
\hline Respondents & Case & Role \\
\hline 1 & A & Department Manager R\&D \\
\hline 2 & A & Department Manager Bridge Construction \\
\hline 3 & A & Structural Bridge Engineer \\
\hline 4 & B & Factory Manager \\
\hline 5 & B & Academic Representative \\
\hline 6 & B & Production Manager \\
\hline 7 & C & Production Developer \\
\hline 8 & C & Process Engineer \\
\hline 9 & C & Chief Engineer \\
\hline 10 & C & Production Manager \\
\hline 11 & C & Product Developer \\
\hline 12 & D & D \\
\hline 13 & D & Copment \& Marketing Manager \\
\hline
\end{tabular}

Secondary data is collected from publicly accessible information and internal documents about the operating climate and policy of every manufacturing company. This data triangulation offered parallel, interpretative and, to some degree, confirmation of the interview results.

Secondary data is collected from publicly accessible information and internal documents about the operating climate and policy of every manufacturing company. This data triangulation offered parallel, interpretative and, to some degree, confirmation of the interview results.

Reduction of data was done by summing up the interviews and transferring them to a database to sharpen, sort, focus and organize the data. It was accompanied by content analysis and coding in relation to usability variables and impact on product design area, first at single case level and then cross-case to identify specific or differentiating characteristics by G. Pahl and W. Beitz (1996). Use output parameters of the manufacturing system as the relation between a product's manufacturing system and manufacturing efficiency. Information was then shown in tables to be able to see trends and draw conclusions.

\section{Results}

The key goals of the market growth initiatives analysed were to identify ways to manufacture goods at a lower cost of production and increased efficiency. While the programs involved developments in technology, the motivating aspect was a requirement or an incentive for creativity to manufacture a product with increased manufacturing capabilities. As the industrial technologies learned evolved and matured, the convergence of production and product growth and greater efficiency became feasible.

For DfP, in the cases examined, both DtX and DfX methodologies were used to sustain or improve efficiency in the stated specifications (viz. productivity factors) for the manufacturing process and to adapt product design to the evolving industrial design area. For instance:

In Case A and Case B, prior to the 'innovations' industrial design engineers and engineering engineers were confined to those specifications according to DfM. With their latest success in producibility variables, the manufacturing advances opened up new possibilities for product design.

In Case A, the bridge's product design model had to suit the prefabrication approach chosen largely because of Design to Cost (DtC) and Design for Lead-Time (DfLT), thus design for manufacturing (DfA) and assembly design was implemented to design a compact and assembly-friendly system (bridge).

In comparison, the combining of materials (steel and concrete) in the production process makes it possible to trim down the dimensions of the bridge as desired to achieve an aesthetically attractive structure or improved preconditions for fitting a bridge to the setting (geographical and geotechnical), thereby increasing the amount of potential designs. 
In Case B, the production methods used in integrated building systems are traditional methods adapted to an automated environment, but with relatively low productivity efficiency on factors such as lead time. Previously, the bathroom floors were built using traditional processes. This was not only a time-consuming endeavour that disrupted the overall manufacturing cycle but also created quality concerns because this form of floor was not appropriate for shipping, an unavoidable part of the prefabrication and assembly process. The construction of this approach was a collaborative project to improve both the fiberglass basin and the manufacturing process using DtX to enhance efficiency on manufacturing variables such as lead time, consistency and cost of production by applying the manufacturing method to the industrial environment and DfX to construct a fiberglass basin suitable for manufacturing operation. Such results support F. Elgh and M. Cederfeldt (2008) the argument that DfP provides a holistic view of the production process and the property of the drug.

Similar to Case $\mathrm{C}$, the existing manufacturing methods in Case D had restrictions on possible product dimensions. The key goal in this case was not to slash manufacturing costs but instead to exploit the potential for improved efficiency and quality that this technology might offer to product design. The twisted holes manufacturing process made it possible to develop and manufacture new-dimensional drills, using twisted cooling channels mounted in the flanges. The superior performance of this new drill model along with the low cost of production made this a successful DfX and DtM alliance.

For one viewpoint, the optimistic impact on factor efficiency and product design space may also have a contrary hand. When seen in Case A and Case B, improved production efficiency and an extension of product design space in one direction may also imply a design space constraint in another direction. For example, by swapping the resource intensive traditional building methods for more effective prefabrication methods that extend the product production area while delivering slimmer construction possibilities, certain new restrictions are imposed on industrial design engineers in implementing modular designs. Using manufacturing methods combinations however can wisely bring the benefits without seeing the downsides.

\section{Conclusion}

Innovative advances in manufacturing (process) processes (e.g. components, tooling, techniques, procedures, etc.), also known as 'technology inventions,' will lead to increased manufacturability and efficiency by increasing the performance of the process system, allowing new product products (NPDs) technologically possible and financially viable. Therefore, it is important to recognize the potential of manufacturing technologies to build or expand product design spaces instead of focusing only on 'manufacturability design' which adapts product concepts to the current manufacturing capacity-framed product design space.

Nevertheless, improved production efficiency and an extension of product design space in one direction could also suggest more design space limitations in another direction. Considering this capacity of manufacturing innovations to influence the space of product design, it can also have a significant impact on the competitiveness of manufacturing companies as another tool for increased innovation Is included.

\section{REFERENCES}

M. Vielhaber and P. Stoffels, P.(2014), "Product Development vs. Production Development," Procedia CIRP, Vol. 21, pp. 252-257.

D. Romero, L. Larsson, A. Öhrwall Rönnbäck and J. Stahre.(2017), "Strategizing for Production Innovation,” The Path to Intelligent, Collaborative and Sustianable Manufacturing, (To Appear).

J. Lessing, L. Stehn and A. Ekholm(2015), "Industrialised House-Building Development and Conceptual Orientation of the Field," Construction Innovation, Vol. 15, No. 3, pp. 378-399.

C. Levandowski, D. Raudberget and H. Johannesson (2014). "Set-based Concurrent Engineering for Early Phases in Platform Development," Proceedings of the 21st ISPE Inc. International Conference on Concurrent Engineering, CE 2014, pp. 564-576, .

J.G. Bralla(1999), "Design for Manufacturability: Handbook,” Ed., New York: McGraw-Hill.

F. Elgh and M. Cederfeldt (2008), "Cost-based Producibility Assessment: Analysis and Synthesis Approaches through Design Automation," Journal of Engineering Design, Vol. 19, No. 2, pp. 113-130.

T-C. Kuo, S.H. Huang and H-C. Zhang (2001), "Design for Manufacture and Design for 'X': Concepts, Applications, and Perspectives," Computers \& Industrial Engineering, Vol. 41, No. 3, pp. 241-260.

I. Gibson, D.W. Rosen and B. Stucker (2015), “Additive Manufacturing Technologies: Rapid Prototyping to Direct Digital Manufacturing,” 2nd Edition, New York, Springer, 2015. 655.

J. Landahl, C. Levandowski, H. Johannesson, R. Söderberg, K. Wärmefjord, J.S. Carlson, J. Kressin, O. Isaksson and J. Vallhagen (2016), "Using Product and Manufacturing System Platforms to Generate Producible Product Variants," Procedia CIRP, Vol. 44, pp. 61-66.

Best Manufacturing Practices Center of Excellence (1999), "Producibility System Guidelines for Successful Companies: The Five Steps to Success," Best Manufacturing Practices: College Park, MD, USA, NAVSO P3687. 
J. Vallhagen, J. Madrid, R. Söderberg and K. Wärmefjord (2016), “An Approach for Producibility and DFMMethodology in Aerospace Engine Component Development," Procedia CIRP, Vol. 11, pp. 151-156.

[12] A.J. Ball (2015), "Identification of Leading Indicators for Producibility Risk in Early-Stage Aerospace Product Development,” Doctoral Dissertation, Massachusetts Institute of Technology (MIT).

F. Eureka (1994), "Design for Manufacture - DFM, Guide for Improving the Manufacturability of Industrial Products," Fabricius, F. (Ed.), Institute for Product Development, Lyngby, Denmark.

M. Bellgran and E.K. Säfsten (2009), "Production Development: Design and Operation of Production Systems," Springer Science \& Business Media.

P.M. Milling and J. Stumpfe (2000), "Product and Process Innovation: A System Dynamics-Based Analysis of the Interdependencies," 18th International Conference of the System Dynamics Society, Bergen, Norway.

J. Stumpfe (2001), "Product Design and Manufacturing Processes: Dynamic Implications for Innovation Management," 19th International Conference of the System Dynamics Society, Atlanta, Georgia, USA.

G. Pahl and W. Beitz (1996), "Engineering Design - A Systematic Approach," 2nd Edition, London: Springer, 1996.

J.G. Bralla, "Design for Excellence,” New York: McGraw-Hill.

S. Elstner and D. Krause (2014), "Methodical Approach for Consideration of Ramp-up Risks in the Product Development of Complex Products," Procedia CIRP, Vol. 20, pp. 20-25.

D. Vazquez-Bustelo, L. Avella and E. Fernandez (2007), “Agility Drivers, Enablers and Outcomes,” International Journal of Operations \& Production Management, Vol. 27, No. 12, pp. 1303-1332.

J.P. Womack, D.T. Jones and D. Roos (2013), "Machine that Changed the World," Simon and Schuster, 1990.

R.K. Yin, "Case Study Research: Design and Methods," Sage Publications.

K.M. Eisenhardt and M.E. Graebner (2008), "Theory Building from Cases: Opportunities and Challenges," Academy of Management Journal, Vol. 50, No. 1, pp. 25-32.

M.B. Miles and A.M. Huberman (1984), "Drawing Valid Meaning from Qualitative Data: Toward a Shared Craft," Educational Researcher, Vol. 13, No. 5, pp. 20-30. 